\title{
ANTROPOLOGIA LITERÁRIA E TEORIA DA SEDU- ÇÃO GENERALIZADA: EMANCIPAÇÃO PELA LEITURA
}

\author{
Larissa Brito dos Santos \\ Mestranda em Letras pela Universidade Federal da Paraíba (UFPB) \\ larissabs1@hotmail.com \\ Fernando Cézar Bezerra de Andrade \\ Doutor em Educação pela Universidade Federal da Paraíba (UFPB) \\ Professor da Universidade Federal da Paraíba (UFPB) \\ frazec66@gmail.com
}

\section{RESUMO}

Este trabalho articula os conceitos de emancipação, da Antropologia Literária proposta por Iser; e o de tradução, da Teoria da Sedução Generalizada de Laplanche, com o objetivo de compreender de que forma a leitura literária pode auxiliar na emancipação do leitor real. A articulação teórica aqui proposta conclui que a leitura e, consequentemente, a experiência estética, também concorrem para a autotradução do indivíduo, processo em que, na perspectiva laplancheana, podem se evidenciar conteúdos inconscientes e pré-conscientes, de caráter enigmático, que aguardam por significação. Essa experiência impelirá a novas leituras, a novas traduções artísticas, favorecendo de novo, na melhor das hipóteses, a reentrada do leitor nos processos emancipatórios em que a experiência estética ajude a traduzir completamente, ou seja, permita completar-se o ciclo pelo qual o sujeito não só se desestabiliza, mas também se reequilibra cognitiva, afetiva e esteticamente.

Palavras-chave: emancipação; autotradução; literatura; antropologia literária; teoria da sedução generalizada.

\section{ABSTRACT}

This work articulates similar paradigms, which are understood to be complementary, comparing the concepts of "emancipation", from Literary Anthropology, proposed by Iser; and "traduction", from Laplanche's Theory of Generalized Seduction, in order to understand how literary reading can aid in the emancipation of the real reader. In this sense, reading (as well as the aesthetic experience) also contributes to the selftraduction of the individual, a process in which, from the Laplanchean perspective, unconscious and preconscious contents, of an enigmatic nature, awaiting signification can be evidenced. Obviously, the aesthetic experience will impell new readings, and, in the best-case scenario, other artistic traductions, helping the reader to reenter the emancipation processes. Thus, the dynamic cycle of aesthetic experience (cognitive, emotional and aesthetical destabilization preceeding a new stabilization) will be completed by Reading.

Keywords: emancipation; selftraduction; literature; literary anthropology; theory of generalized seduction. 


\section{Introdução}

Na ótica aqui adotada, a literatura é considerada por um caráter antropológico, pois se configura como uma necessidade humana. Os processos que envolvem a atividade de leitura - conscientes e inconscientes - são denominados por Iser (1999) como ficcionalização, ou seja, a atividade de preencher vazios típicos da subjetividade da arte.

O processo de leitura, como proposto por Iser, é capaz de emancipar o leitor real, tornando-o capaz de compreender textos de níveis de complexidade cada vez maiores. Essa emancipação se concretiza por haver uma evidenciação de processos do inconsciente parcialmente traduzidos, há muito recalcados, ainda que o leitor não se dê conta disso.

A motivação deste artigo surgiu a partir da semelhança entre os conceitos de emancipação e autotradução que, depois de articulados, revelaram similaridades entre a teoria do campo da literatura e a do campo psicanalítico, ambas voltadas para explicar os múltiplos sentidos atribuídos aos vazios da existência, em um processo de humanização. Humanização, nesse contexto, refere-se ao conceito postulado por Candido (2004, p. 177), ao afirmar que as manifestações ficcionais são capazes de reorganizar materiais psíquicos do domínio do inconsciente, além de organizar a própria compreensão de mundo que temos, ou seja, de nos fazer vivenciar acontecimentos que propiciam reflexões críticas da sociedade.

\section{A antropologia literária e a emancipação do leitor}

A Antropologia Literária é uma teoria criada pelo alemão Wolfgang Iser (1999), que busca inferir porque os seres humanos se envolvem em um jogo baseado em atos de 
fingir e porque esse fingimento, declaradamente fictício, é capaz de proporcionar emoções de nível consciente e inconsciente nesses sujeitos. A ficcionalização possibilita que outras existências sejam vivenciadas e auxiliem na compreensão do mundo real. Essas disposições aos atos de fingir não são apenas produto da arte, mas nelas se encontram deliberadamente, atualizando as demais disposições que configuram o que nos é propriamente humano, sob a relação entre fictício e imaginário proposta pelo autor.

Entendida a partir dessa relação entre o real e o imaginário, o fictício não se opõe à realidade, pois o ato de fingir ultrapassa qualquer sistema referencial; ao mesmo tempo, confere ao imaginário uma dimensão real, na medida em que, ao ganhar forma no texto, penetra e age no mundo. A literatura, portanto, é um mundo transgredido e reformulado, que necessita ser compreendido e experimentado (OLIVEIRA, 2015, p. 107).

Para Iser, a leitura literária é a concretização de um processo considerado necessidade humana, a ficcionalização. Ficcionalizar, ou seja, preencher as incompletudes que circundam e compõe as artes e o cotidiano, é criar jogos nos quais entram em cena os atos de fingir, que são considerados de teor antropológico.

[...] a arte constitui um componente inevitável da cultura. E uma vez que a cultura se tornou - ainda que só recentemente - o principal interesse da antropologia, a literatura como característica constitutiva daquela adquire necessariamente uma dimensão antropológica própria (ISER, 1999, p. 150).

Desse modo, a ficcionalização se caracteriza como uma necessidade, por ser uma ação inerente ao ser humano, que ocorre nas mais diversas situações, desde a leitura de um poema até uma reflexão sobre um acontecimento que perpassa a rotina do indivíduo. 
Para Iser, ficção se apresenta no sentido de "algo feito", "algo moldado", e não de algo falso ou irreal, como é comumente apresentado.

Sendo assim, a ficcionalização se constitui como um processo de "construção", na qual damos sentido aos vazios da realidade, moldando-os. Caracteriza-se então como um procedimento que faz parte da vida e da cultura humana, um processo antropológico, visto que evidencia características humanas.

Wolfgang Iser admite em sua teoria que o texto literário só se realiza a partir da sua interação com o leitor, como pode ser observado no trecho a seguir, em que o autor identifica como esse processo de substituição ocorreu no contexto da década de 1960:

\begin{abstract}
A busca da intenção autoral foi substituída pelo exame do impacto que um texto literário era capaz de exercer num receptor em potencial. Não sendo mais obrigatória a identificação da mensagem da obra, surgiu um interesse pelo que, desde então, se denominou processamento do texto, isto é, o que acontece ao texto no ato da leitura. Por fim, a relação triádica entre autor, texto e leitor se tornou objeto de estudo (ISER, 1999, p. 25-26).
\end{abstract}

De acordo com a proposta iseriana, o texto literário possui estruturas que devem ser ativadas pelo leitor, por meio da leitura. Sendo assim, a obra não acontece sozinha, estando condicionada à interação, o que faz com que possua um caráter virtual. "A obra literária se realiza então na convergência do texto com o leitor; a obra tem forçosamente um caráter virtual, pois não pode ser reduzida nem à realidade do texto, nem às disposições caracterizadoras do leitor" (ISER, 1996, p. 50).

A participação do leitor na construção de sentido da obra literária é um dos interesses primordiais da Antropologia Literária, que busca compreender por que o ser hu- 
mano necessita de tais fingimentos e cria mundos possíveis em decorrência daquele no qual estão inseridos, como explica Santos no trecho a seguir:

Interessada no engajamento do leitor numa atividade que envolve um fingimento, a teoria iseriana empenhou-se em conhecer os atos impulsionados por tal fingimento, mesmo sendo este uma ilusão. $O$ fato de empenharmo-nos em "atos de fingir" nos denuncia como apreciadores da vivência de ilusões. Depreende-se que a vivência do fingimento, por assim dizer, pode revelar algo sobre nós (SANTOS, 2009, p. 211).

O modo como atribuímos sentido a um texto literário está intrinsecamente relacionado às nossas experiências, leituras e conhecimento de mundo, pois utilizamos o nosso repertório buscando preencher as lacunas, as incompletudes que estão presentes em um texto literário. No primeiro momento, identifica-se o repertório do texto, constituído de elementos que revelam algo familiar ao leitor - que podem estar relacionados a outros textos, normas sociais, fatos históricos ou referentes ao senso comum.

Note-se que o repertório tem o poder de iniciar a comunicação entre o texto e o leitor. O texto adquire múltiplos sentidos, considerando que o nível cognitivo e as experiências/repertório de cada leitor em potencial certamente serão distintos. Cada sentido atribuído será único, pertencente àquela relação específica entre texto e leitor. O sentido que o leitor irá atribuir ao texto literário está diretamente relacionado às suas experiências. Se o texto não apresenta características familiares que possibilitam a interação, acaba por exigir mais do leitor por se mostrar mais complexo, devido à discrepância entre os repertórios. O mesmo pode acontecer com textos muito simples, ou muito populares, que não desafiam a atribuição de um sentido à obra, gerando desinteresse e levando ao abandono do texto. 
O sentido, na perspectiva iseriana, refere-se à "síntese interna que resulta na concretização da experiência estética, ou seja, a formulação do objeto estético" (SANTOS, 2015, p.15). O objeto estético é produto da interação, ou seja, o resultado da transformação e atualização do texto em obra literária que proporcionará a experiência estética.

Iser afirma que esses procedimentos acontecem de forma inconsciente e culminam na atribuição de sentido à obra, dando origem a um efeito, que não pode ser compartilhado ou descrito, mas apenas vivenciado, como assevera Santos:

\footnotetext{
Por que, então, num primeiro contato atribuímos características familiares ao estranho? Para compreender o diferente, primeiro o associamos ao conhecido. Quando tal associação é realizada a ponto de compreendermos o não-familiar, o efeito desaparece, já que para sê-lo precisa não se cristalizar em algo além de si próprio. Está aí o seu matiz estético (ISER, 2007, p. 65-66).
}

Todo o processo de leitura tem como objetivo a atribuição de sentido feita pelo leitor ao texto. Após a concretização desse processo o leitor vivenciará esse sentido, transformando-o em significação, que é resposta dada ao sentido e que se configura em sua vida pessoal. A significação pode acontecer em um momento posterior à leitura, quando este consegue relacionar o sentido do texto a um acontecimento singular de sua existência.

Esse procedimento promove um avanço cognitivo e emocional que gera a emancipação do leitor, tornando-o capaz de atribuir múltiplos sentidos e expandir suas ficcionalizações. Com isso, pode ler, compreender e significar textos cada vez mais complexos ou realizar outros níveis de leitura com obras lidas anteriormente, devido à ampliação de seu repertório, possibilitando outras combinações entre as lacunas textuais. 
Jauss então atribui prazer e conhecimento à experiência estética e, segundo ele, nisso consiste o caráter transgressor da arte: A obra recebida, compreendida e apreciada (perde o seu caráter opressor) incitaria o destinatário a participar da liberdade conquistada, ou seja, a emancipação (SANTOS, 2014, p. 334).

Dessa forma, compreendemos que a leitura (desde que feita em níveis cognoscitivamente apropriados) é a maneira mais efetiva de tornar o leitor mais competente e apto a textos mais exigentes de cognição e imaginação, ampliando os horizontes e repertórios, o autoconhecimento (porque ler é autotraduzir-se) e modificando o cotidiano do leitor.

\section{O processo de autotradução segundo a teoria da sedução generalizada}

A teoria da sedução foi, inicialmente, desenvolvida por Freud (entre 1895 e 1897), buscando compreender os efeitos de acontecimentos de uma experiência sexual prematura, geralmente ocorrida na infância e conduzida por um adulto perverso, que desencadearia uma ação patogênica.

Ele inferiu, à época, que a origem da sexualidade na infância estivesse nesse ataque de natureza sexual, inaceitável para o sujeito e mantido inconsciente graças ao recalque. Porém, constatando que essa hipótese não se sustentaria - em razão de não identificar empiricamente a sedução em todos os casos relatados -, abandonou essa teoria em setembro de 1897, passando então a recorrer a outros elementos da experiência psíquica para manter sua pesquisa.

Jean Laplanche releu a teoria da sedução (que veio a chamar de restrita), encontrando nela um paradigma que considerou válido - a despeito dessa explicação não caber em todos os casos empíricos (já que nem todo mundo foi sexualmente abusado na infância). O psicanalista entendeu nela o modelo da origem da sexualidade infantil, gerada no 
encontro (não necessariamente pedofílico) entre adultos com sexualidade inconsciente e crianças sem essa marca.

Laplanche (1988) entende que na infância todos somos originalmente passivos quanto à exposição à sexualidade infantil, implícita nos cuidados administrados por esses adultos. Na relação com as crianças, os adultos, dotados de inconsciente sexual (portanto, de sexualidade infantil perversa polimorfa, como a descreve Freud), cuidaram de nós e enviaram mensagens pré-conscientes, contaminadas por suas fantasias inconscientes. Essas mensagens não foram natural nem suficientemente traduzidas, mas recalcadas, deixando um resto por ser significado - que vem a constituir o inconsciente na criança.

Logo, a passividade infantil se explica porque a criança não está pronta para corresponder às fantasias sexuais infantis recalcadas que o adulto lhe dirige, sem o saber, quando com ela se relaciona - cuidando, protegendo, preparando para a vida, mas, também, enviando-Ihe mensagens com conteúdos pré-conscientes, carregados de sexualidade infantil.

Esse binômio passividade/atividade não é algo facilmente mensurável nem precisamente datável, mas, compondo o paradigma historicista laplancheano, deve ser levado em conta para explicar o mistério de uma sexualidade que não se apoia sobre o biológico, dado ser precoce e inadaptativa.

Ora, ao resgatar, como paradigma intersubjetivo, a teoria da sedução restrita, generalizando-a para aplicá-la a todo processo de humanização, Laplanche ressalta que ela se desenvolve a partir de três fundamentos: o temporal, o tópico e o tradutivo.

O aspecto temporal indica que a sedução se dá a partir de pelo menos dois acontecimentos separados no tempo. O primeiro causará terror ao sujeito, que não está pronto para uma ação sexual altamente significativa, mas a significação dessa experiência não 
é assimilada. Apenas no segundo momento, quando a lembrança é revivida, ela surge caracterizada como um trauma.

Já o aspecto tópico é uma defesa patológica que se dá a partir do recalcamento. Na primeira experiência o indivíduo é atacado externamente, mas não tem meios de defesa. Na segunda, já possui os meios, mas não é capaz de produzir defesa, visto que é tomado pelo trauma decorrente da tomada de consciência dos conteúdos sexuais, no segundo tempo - o da rememoração (que é, também, o da significação).

O terceiro aspecto, o tradutivo, consiste na relação entre as cenas, ou seja, a forma como aquelas situações específicas foram assimiladas pelo sujeito. Desde a infância, essa assimilação nem é direta, nem totalmente consciente, mas, ao contrário, revela um esforço particular de reorganização dos conteúdos da sedução em materiais que recebem destinos diferentes. O que for considerado aceitável é integrado pelo eu, mas o que é ameaçador (frequentemente ligado à passividade originária) é recalcado.

O recalque é a operação psíquica que retira da consciência material perigoso às representações que o eu faz de si. Porém, nesse processo, o eu não é completamente eficiente, restando sempre lacunas. Nesse sentido, o recalcamento aparece tanto como uma estratégia de manejo do sexual infantil através de traduções (pelas quais o material psíquico dissonante é parcialmente reintegrado em novas associações de representações mais admitidas à consciência); quanto, por outro lado, ele mesmo como produto de uma falha parcial na tradução, que irá suprimir uma representação e mantê-la no inconsciente. De um lado, para Freud, a sedução seria consequência de acontecimentos pontuais que ficavam marcados no inconsciente e eram retomados no episódio traumático, considerando a sexualidade como um processo externo que se interioriza a partir da experiência sedutora. De outro, Laplanche reformula essa concepção considerando que a sedução é 
uma construção intersubjetiva, reforçando este último autor a impossibilidade de identificar uma situação traumática inicial, visto que cada episódio iria remeter-se a um anterior.

Desse modo, a sedução deixa de ser patológica e passa a ser generalizada, caracterizando um processo da construção psíquica e levando em consideração que o adulto não precisaria necessariamente ser um dos pais (nem, tampouco, pedófilo), visto que a família pode ser constituída em diversas outras configurações e a sexualidade infantil, perversa e polimorfa que caracteriza o inconsciente, passa a ser constitutiva de todo ser humano - não porque, como queria Freud, brotasse do corpo, mas, sim, como pretende Laplanche, resulta do (des)encontro de adultos com inconsciente sexual e crianças desprovidas desse lugar psíquico. A sedução, nesta última acepção, é um traço da condição humana, necessário para a humanização.

A teoria da sedução generalizada considera inevitável para o indivíduo que se depare com a situação antropológica fundamental, ou seja, com o conflito entre linguagens, que provoca a sedução originária a partir de uma relação entre adulto e criança. Nessa relação, o adulto, dotado de seu inconsciente repleto de mensagens sexuais que se constituíram de resíduos da infância, transmite essas mensagens para a criança, que por sua vez não possui disposições sexuais genéticas.

Ao se deparar com esse conflito entre linguagens (ao receber mensagens as quais não é capaz de compreender, visto que lhe falta o domínio da linguagem sexual perversa polimorfa), de acordo com Laplanche (2006) é necessário recorrer à tradução e consequentemente lidar com as falhas desse processo, já que a mensagem é composta de reminiscências do inconsciente que não poderão ser completamente decifradas. Essas 
mensagens são registradas no inconsciente e trazidas à tona em uma situação posterior, objetivando a sua tradução, mas, inevitavelmente, recalcando parte da mensagem.

A sedução originária, produto da situação antropológica fundamental, se constitui como o momento que dá início a todo um processo que se repetirá diversas vezes ao longo da existência do indivíduo: as sucessivas tentativas de autotradução e autointerpretação.

No processo de autotradução, servem como auxílio importante os dispositivos culturais. Após o confronto com as mensagens enigmáticas fornecidas pelo adulto, a criança precisa estabelecer meios e recorrer a códigos na tentativa de traduzi-las. Se essas mensagens escapam dos códigos relacionais à disposição, a cultura age como um intermédio, a partir de esquemas narrativos pré-formados que fornecem subsídios para a transposição das mensagens, ainda que seja impossível recuperá-las completamente.

Daí o caráter generalizador da teoria de Laplanche que, preocupando-se em preencher as lacunas deixadas por Freud, valoriza-a para nela evidenciar seus traços verdadeiramente universais, antropológicos. Já não se trata de empiria, mas do reconhecimento de traços comuns à experiência humana, ligados à diferença entre o psiquismo adulto e o infantil - bem como aos efeitos das condições que permitem tal diferença.

Como a tradução, tal qual o próprio episódio sedutor, se dá em dois momentos distintos - o momento em que a mensagem é recebida e o momento em que a mensagem é finalmente traduzida (parcialmente) ou recalcada -, muitas são as mensagens que permeiam o indivíduo à espera de uma tradução. Experiências formadoras, como o próprio ato de leitura, revelam algo sobre nós mesmos, seja nas pré-disposições, sensações e até na rejeição do conteúdo literário. Quando lemos, ativamos procedimentos inconscientes que nos auxiliam no processo de autotradução dos enigmas sexuais infantis. 


\section{Articulação teórica entre os conceitos de emancipação e tradução}

O confronto entre sistemas psíquicos - um com conteúdos sexuais recalcados, outro sem - que caracteriza a situação antropológica fundamental é um processo descrito para todos os seres humanos, conforme afirmou Laplanche (1988). Um ponto de articulação entre as teorias que ora analisamos, a Teoria da Sedução Generalizada (TSG) e a Antropologia Literária, consiste no fato de que a literatura também se insere no campo da antropologia, visto ser considerada uma necessidade humana.

Do ponto de vista artístico - mais especificamente o literário - essa necessidade caracteriza-se a partir do processo de ficcionalização: precisamos dar sentido aos vazios da nossa existência. Quando o indivíduo, geralmente a criança, se depara com mensagens impossíveis de serem decifradas, ao menos naquele momento, essas mensagens podem ser caracterizadas como contendo vazios, que provocam o psiquismo a preenchê-los. Não é demais reconhecer diferenças: enquanto a TSG enfatiza a dificuldade da criança em traduzir a mensagem do adulto, a Antropologia Literária acentua o aspecto tradutivo.

Não obstante essa distinção importante, ambas as teorias convergem: é por causa da dificuldade de tradução que a ficcionalização aparece - o exercício de explicar, teorizar, baseia-se, primariamente, na atividade de fantasiar. Ficcionalizar e fantasiar são processos muito semelhantes, dando-se o primeiro sempre no plano da consciência, enquanto a fantasia, no mais das vezes, do ponto de vista psicanalítico, tem sua eficácia derivada dos conteúdos advindos do inconsciente - repercutindo, obviamente, na vida de vigília, mas apenas de forma velada, indireta, sem a necessidade da intervenção consciente do eu. 
Ambos os processos se relacionam de forma que as lacunas deixadas pelo episódio primário da sedução precisarão ser traduzidas, constituindo o episódio secundário e dando sentido àquelas mensagens que antes careciam de significados, processo análogo ao da leitura literária, como proposto por Wolfgang Iser. Neste sentido, a articulação aqui pretendida enfatiza: a ficcionalização também está correlacionada ao impulso para traduzir material inconsciente. Ninguém ficcionaliza sem se implicar subjetivamente.

Laplanche mostra a importância de considerar que o adulto sedutor não se resume ao pai ou a mãe daquela criança seduzida, mas se estende a outras configurações familiares. Aqui, ampliamos essa compreensão para que ela seja capaz de abranger também a ficção, se caracterizando também como possível sedutora nesse processo.

A literatura é geralmente abstrata e repleta de traduções possíveis às mensagens enigmáticas, incluindo as de caráter sexual, que necessitam ser traduzidas, seja na forma do recalcamento, seja na tradução parcial, em um momento posterior ao do episódio sedutor, assim como o processo descrito na TSG.

Ao mesmo tempo, quando o texto literário é marcado por vazios, quebras da good continuation, negações etc. - lacunas propositalmente construídas por quem escreve, de modo a tornar o texto mais artístico - a obra evidencia um movimento de sedução, já que os processos descritos por Iser apontam para o empenho do leitor em completar o texto criando uma obra em que, inevitavelmente, quem lê se deixa implicar e também seduzir. A leitura motivadora é aquela em que o leitor está seduzido, seja pelo enigma evocado nas estruturas textuais, seja pelas traduções construídas na produção da obra.

Assim, o processo de leitura literária, como proposto por Iser, envolve procedimentos inconscientes (neste caso, fora da consciência metanarrativa, não necessariamente na acepção psicanalítica do inconsciente sexual), que levam em conta o repertório do 
leitor, suas predisposições à leitura de um determinado texto, seus valores, seus medos, outros textos lidos anteriormente, etc. Todos esses procedimentos são levados em consideração e provocam sensações, desde a negação, a quebra da good continuation, a significação, o prazer (para a teoria psicanalítica, originariamente sexual e, no caso da leitura, também sublimado) e até a própria catarse, proposta por Aristóteles em sua Poética (2004).

Essas sensações são experimentadas, ainda que não sejam compreendidas. Elas podem caracterizar ambos os episódios da sedução, seja do texto que transmite mensagens que ainda não podem ser decifradas, mas que aguardam ser traduzidas; seja ao trazer à tona episódios vivenciados anteriormente, tanto por meio de outras ficções, quanto por intermédio de um episódio de sedução que aguardava tradução, por um conjunto de sensações vivenciadas a partir da leitura.

Nesse processo, não é demais lembrar, o outro lado da motivação para ler encontra-se na ajuda que a leitura traz como uma modalidade para as traduções dos enigmas inconscientes. Ler torna-se, com isso, sinônimo de atribuir significados, sentidos, decifrando enigmas (já não mais necessariamente sexuais, mas, com certeza, estéticos e existenciais.). O texto, como o adulto, com sua sexualidade infantil, perversa e polimorfa mas também como o psicanalista na situação transferencial (Laplanche, 1992) -, excita e seduz, convocando o leitor - que, por seu repertório, na comparação teórica, denuncia-se enquanto já dotado de inconsciente, é capaz de participar ativamente na produção de significado e na experiência estética.

Por isso mesmo, a ênfase na relação entre leitura e tradução nos leva à relação estabelecida entre os conceitos de emancipação e autotradução. O caráter transformador da literatura é algo que Iser demonstra ter sido comprovado através de seus estudos de 
teoria literária. O procedimento que explica a possibilidade de um salto qualitativo gerado a partir da leitura de uma ficção denomina-se emancipação.

Wolfgang Iser (1999) afirma que quando lemos um texto, aprendemos com ele, desde a ampliação do nosso repertório até a capacidade de compreender melhor outros textos cada vez mais complexos, num processo que se assemelha ao de teorias da aprendizagem propostas por Vygotsky (1993) no crescimento da zona de desenvolvimento real ou Piaget (1986) no alargamento das estruturas cognitivas.

Para que haja emancipação é necessário que o texto cumpra condições específicas, com um nível de dificuldade adequado para quem está lendo, de acordo com seu repertório e que não vá além nem aquém de suas capacidades cognitivas. Esse aspecto é relevante, visto que textos que não desafiam o leitor a buscar a compreensão não promovem a emancipação. Do mesmo modo, textos que vão muito além do que já é conhecido pelo leitor, tornam a atividade de compreensão uma tarefa muito difícil, por vezes impossível, que pode levar até mesmo ao abandono do processo, gerando desinteresse e inibindo a emancipação.

Pela perspectiva psicanalítica, se o texto vai muito além do repertório do leitor, pode perder sua capacidade de seduzi-lo, ou seja, potencialmente não provocará mensagens enigmáticas que demandem traduções. O texto é abandonado, muitas vezes, por não excitar o leitor, envolvendo-o no pacto ficcional que retoma, no fundo, o jogo de sedução generalizada: cuidar e desejar, da parte do adulto, mas gozar e excitar-se ao ser cuidado, da parte da criança, que passará a ter em si uma força a impeli-la a funcionar autonomamente - assim como a leitura, uma vez emancipatória, impele a mais leituras, a mais experiências estéticas. 
As mudanças na vida de um indivíduo proporcionadas pela literatura, assim como o desenvolvimento do autoconhecimento, são consequências da experiência estética. Articulando com a TSG podemos afirmar que a leitura literária é motivadora de um processo de autodescoberta que proporciona que diversos conflitos, aguardando por tradução, sejam evidenciados, em maior ou menor grau, a depender do indivíduo e da situação específica.

Em outras palavras, dar sentido aos vazios da existência, assim como às mensagens enigmáticas que não somos capazes de compreender num primeiro momento, faz parte de um processo autotradutivo e a partir dele nós nos transformamos, nos emancipamos e nos tornamos capazes de traduzir cada vez mais conflitos, decifrando materiais inconscientes que há muito aguardavam por essa autoteorização. Em suma, emancipar-se é humanizar-se.

\section{Para concluir: o paradoxo da emancipação de um sujeito dividido}

Uma pergunta ainda é cabível: quem se emancipa, se considerarmos a perspectiva psicanalítica segundo a qual o sujeito é irremediavelmente dividido? O inconsciente não se emancipa, é claro, já que ele é feito de enigmas. A emancipação, nessa articulação, não pode ser tomada como uma resolução da divisão interna, mas, como na metáfora de Iser, um enriquecimento: o que se enriquece, portanto?

Uma resposta primeira é: o eu. Essa estrutura autorreferente, modifica-se em sua organização e pode ganhar em flexibilidade e estabilidade. Ao traduzir melhor seus enigmas, o sujeito reconhece-se com menos sofrimento, menos sintomas, menos soluções 
infelizes para a tensão que o constitui. Há mais integração, no psiquismo, de materiais oriundos do inconsciente - este, jamais integrado, incluído.

Mas, além disso, é preciso reconhecer que o próprio psiquismo se enriquece, pois encontra na ficcionalização, uma forma de manter a própria dinâmica. Ficcionalizar e criar estão intimamente relacionados, e a criatividade é entendida na psicanálise, desde Freud (1974), como um indicativo da saúde psíquica, dado não apenas sermos seres de cultura (devendo, pois, aprender a criar), mas também por não podermos, em função dos limites da vida (e do próprio psiquismo), realizar todos os desejos inconscientes.

A imediata, completa e irrestrita realização destes desejos, em última instância, implicaria eliminação automática do psiquismo. Ser sujeito é, igualmente, ser capaz de substituir uma impossibilidade por outra realidade possível apenas no mundo da fantasia: a isto não se pode associar, afinal, o ficcionalizar analisado por Iser?

\section{Referências}

ARISTÓTELES. Arte poética. São Paulo: Martin Claret, 2004.

CANDIDO, Antonio. $O$ direito à literatura. In: Vários escritos. São Paulo: Duas Cidades, 2004. p. 169-191.

FREUD, Sigmund. Extratos dos documentos dirigidos a Fliess. In: FREUD, Sigmund. Edição Standard Brasileira das Obras Psicológicas Completas de Sigmund Freud. Rio de Janeiro: Imago, 1974 [1897]. p. 100-164.

ISER, Wolfgang. O ato da leitura: uma teoria do efeito estético. São Paulo: Editora 34, 1996.

ISER, Wolfgang. O que é antropologia literária? In: ROCHA, João Cezar de Castro (org.). Teoria da ficção: indagações à obra de Wolfgang Iser. Rio de Janeiro: EdUERJ, 1999.

LAPLANCHE, Jean. Teoria da sedução generalizada e outros ensaios. Porto Alegre: Artes Médicas, 1988. 
LAPLANCHE, Jean. Novos fundamentos para a psicanálise. São Paulo: Martins Fontes, 1992.

LAPLANCHE, Jean. Sexual: a sexualidade ampliada no sentido freudiano (2000 - 2006). Porto Alegre: Dublinense, 2006.

OLIVEIRA, Rejane Pivetta de. Da antropologia literária de Iser à análise da literatura na cultura. In: FEIJÓ, Elias J. Torres; VÁZQUEZ, Raquel Bello; SAMARTíM, Roberto. (orgs.). Estudos de AlL em Teoria e Metodologia: relacionamento nas lusofonias II. Coimbra: AIL Editora, 2015, p. 105-114.

PIAGET, Jean; INHELDER, Barbel. A psicologia da criança. São Paulo: Difel, 1986.

SANTOS, Carmen Sevilla Gonçalves. Teoria do efeito estético e teoria histórico cultural: o leitor como interface. João Pessoa: Bagaço, 2009.

SANTOS, Carmen Sevilla Gonçalves. Por que (não) precisamos ler (e ensinar) literatura? In: SÁ JÚNIOR, Lucrécio Araújo de; OLIVEIRA, Andrey Pereira de (orgs.). Literatura e ensino: reflexões e propostas. Natal: EDUFRN, 2014. v. 1, p. 71-90.

SANTOS, Larissa Brito dos. Da ficcionalização em animação de Curta-metragem para o ensino da leitura literária na Educação Infantil: a criação de um Roteiro Didático Metaprocedimental. Relatório Final apresentado à Coordenação do PROLICEN/UFPB. João Pessoa, 2015.

VYGOTSKY, Lev. Semyonovich. Pensamento e linguagem. São Paulo: Martins Fontes, 1993.

Recebido em 06 de maio de 2019.

Aceite em 08 de julho de 2019. 